\title{
The Design and Manufacturing of Essential oil Distillation Plant for rural poverty Alleviation in Ethiopia.
}

\author{
Abebe Kebede* and Mesele Hayelom*
}

\begin{abstract}
The paper presents economic value of the design and manufacturing of essential oil production plant as a strategy for rural poverty alleviation in rural Ethiopia. The level of technology for small scale essential oil industry is characterized for rural community in Ethiopia. The adaptation of oil distillation technology for essential oil production is proposed for small scale industrial entrepreneur. Steam distillation method is selected considering the constraints to meet the socio-economic level of the rural community. The distillation plant has been modelled based on local resources and the first prototype has been manufactured and tested. The study showed that the small scale manufacturing industry in the country do not have the capacity to manufacture the complete distillation plant system with the required precision for standard quality of oil at affordable cost. Thus, the design and the experiment in the use of a prototype small size distillation unit showed that the technology is appropriate for essential oil distillation with low cost and minimal decrease in oil quality.
\end{abstract}

Key words: Small scale essential oil industry, technology characterization, rural poverty alleviation, low cost manufacturing distillation unit.

\section{Introduction}

$S_{\text {noticed a prime mode of growth in }}$ many developing countries. The experience of many developing countries currently with high economic transition like Japan china, India, Korea is a case in history (Romijn 2001). For instance, as early as 1900, before Japanese technology became self-reliant, the products of small scale industries made up a high percentage of Japan's exports (Takeshi 1990). For countries like Ethiopia where more than $85 \%$ of the population heavily depend on subsistence agriculture in rural areas (FAO, 2003), the development and promotion of small-scale agro-industries is a prime mode of rural development. Recent experiences of Ethiopia in few sectors by government initiative in small-scale industries have shown a positive impact of economic growth. For example, the promotion and technology adaptation of Treadle water pump for rural areas has produced many direct and indirect economic advantages.
Technological problem solving in rural areas is the direct advantage while the job creation in the small-scaled manufacturing firms is the indirect advantage. Small-scale agro- processing industries, which are based on the local agricultural resources and rural labour force, have significant impact in bringing sustainable rural development.

Ethiopian is endowed with a vast number of aromatic plants which have been used traditionally for different purposes. The country's geography ranging from the worlds low land Dalul to as high as Ras Dashen Mountain, from arid zone to high precipitation areas is very suitable to cultivate international competitive commercial agricultural products (EI-Namki, (2003). For example, Coulter (1987) cites official estimates in 1981 of 23,000 tonnes pa for the potential production of olibanum in Ethiopia. Having such suitable agricultural zones, African Laboratory of Natural products (ALNP) has proved that the country can benefit by cultivating world's first classed aromatic plants for essential oil production.

\footnotetext{
"Department of Mechanical Engineering, Mekelle University, ,Mekelle, Ethiopia abebe2005@yahoo.com Acknowledgment-The author acknowledges Mekelle University for funding this research work.
} 
The essential oil industry is an agrobased industry, which involves cultivation and distillation activities. It can involve the rural population by having them produce raw materials and by creating job opportunities in the processing of the oils (De Silva, 1998). Distillation of essential oil is relatively uncomplicated. It can be done in rural areas, where the raw materials are produced. Both the technology and the skills required are not sophisticated. The investment required is also relatively low. As a source of energy, different materials like fuel wood or fuel oil could be used. Essential oils are extensively used globally for food flavouring, fragrances, aromatherapy and pharmaceuticals. Their wide industrial applications make an interlocked connection with industrial growth vs. essential oil demand. The world growth in industrialization has increased the worldwide market for essential oils to US\$2.6 billion, with an annual growth rate of $7.5 \%$. Fig 1 shows the country's import in 1999-2001. The value has decreased for 2000 and 2001 years compared to 1999, due to the Ethiopia-Eritrea war. This value is predicted to increase following the growth of cosmetic, food and pharmaceutical industries. The Ethiopian essential oil research center has collected and analyzed the chemical components of more than 90 types of essential oils aroma plants and their world market value.

Unavailability of small-scale adapted technology based on the socio-economic level of the rural community, lack information on the social and economic benefits to be derived from the industrial utilization of aromatic plants, and the low priority given by the government have been a major factors impeding the development of the essential oils industry in Ethiopia (De Silva, 1998; Romijn 2001). The high low-wage labour in rural community, the high renewable aromatic resources in the country, impressive local and international market demand of essential oils, and the good socio-cultural condition of rural communities favour the development of appropriate technology input to the sector. This paper showcase an effort at design and manufacturing of a prototype low cost smallscale essential oil distillation plant adaptable to the rural community.

\section{Characterization of Small-Scale Essential Oil Industries for Rural Communities}

One of major problems of essential oil industry in the country, like other small-scale industries, is scarcity of adapted technological input in the required level. The technological characteristics of small-scale industry can be divided in to seven which include; economics of the scale, Technological base, infrastructure base, Technological level, labour intensity, linkage pattern, and their impact on environment and biodiversity. Evaluation of these factors is Critical for the design and introduction of appropriate technology for a profitable small- scale agro-industry in a society.

Economics of scale

The small industrial units, by assumption, limited scale of manufacturing operations characterised by low productivity and output. This is usually interpreted in terms of the labours involved in the production process. The Korea and Taiwan experiences [Ho, 1980], identified appropriate size of labour for efficient small-scale industries as between 5 -49 employees agro- based smallscale industries such as essential oil industries. The capitalization depends on the financial capacity and the size of resource availability to the entrepreneur(s).

Technological base

Small scale industries depend for their equipments and the process technology on limited numbers of resources that start with the entrepreneurs' own technical expertise, medium and/or large firms that provide the technology and government and NGO institutions desirous to support a measure of indigenous technology. On current situations in rural areas of the Ethiopia, the targeted entrepreneurs have never experienced the industry. The level of technical skills is also very low in rural communities. Therefore, the technical expertise for this industry can be optimized by selection of technological level in the design processes and by providing shortterm trainings.

\section{Infrastructure base}

The infrastructure required for a small-scale industry depends on the size and type of the industry, the type of product and availability of raw materials input. In the case 
of essential oil industries, the plant is supposed to be placed near the source of raw materials for continuous and cost effective operation. For the current condition of the rural areas where no electricity available, biomass can be used as energy source for the distillation unit. Most of the oil produced can stay long period without spoil. Therefore, small-scale essential oil industries can be introduced to the rural community without expensive infrastructure requirement.

Technology level

The technical skill of the operator determines the level of technology in smallscale industries like essential oil industry. The industry in the rural community is to be operated by farmers on their own. This leads the level of technology to be used very low. Optimization of quality of the product and the level of technical skill required is very important in selecting appropriate essential oil industrial technology. Technological level is also connected to the amount of investment required by poor farmers.

Labour Intensity

Aggregated data consistently show that increasing size of technology is associated with decreasing numbers of workers relative to the capital. Labour intensive small size industries are a favourite argument of the Ethiopian economic condition where labourintensive industries are the solution for the current high unemployment rate. Several factors could actually lead to this labour intensity. The degree of technology sophistication, informal sector more inclined towards substituting capital with labour and employing low skill, minimum wage-tied labour, and the economics scale discussed above are the main factors in determining labour intensity of a small-scale industry. Technologies for essential oil industries can be chosen from the lowest technology to the highest technology with minimal change in oil product quality. This creates an advantage for the industry to be introduced in the rural community, which is positive for the above factors.

\section{Linkage pattern}

As for the small scale producers in

rural areas, integration with central downstream processing factories in the country would be essential to have a regular market for the primary products. The linkage between the end users and the small-scale industries is very important factor to have a profitable industry. The end users can be an exporter or a factory. As indicated in Figure 1,, Ethiopia is importing a considerable amount of essential oil for local factories. The development of essential oil industry in the country leads to save this foreign currency. The high world market demand of essential oils can also be an attractive drive to introduce small-scale essential oil industry as a source of foreign currency. Therefore, it can be concluded that the international and local demand of essential oil is at hand if the industry is introduced.

\section{Impact on the Environment and Biodiversity}

The environmental and biodiversity impact of essential oil industry can be seen in two dimensions: the source and cultivation of aroma plants for essential oil production and the source of energy used in the distillation process. Selective cultivation of high yield aroma plants can result a loss of biodiversity. The use of inorganic fertilizers during cultivation can also result loss of soil fertility due to their long term harmful effect. On the contrary, the use of degraded land for the cultivation of aroma plant can bring a sustainable environment in the area. The source of energy for the steam generation can also be a source of environmental degradation. In rural communities, the use of modern fuel for the steam production is not feasible both in terms cost and environmental effect in the short and long run. The use of renewable energy source from bio-energy is the ultimate solution. Sustainable biomass production to use as energy source should be taken into account in the introduction of this small scale industry to the rural community.

Project Experience: Developing Low Cost, Small-Scale Essential Oil Distillation Plant

The project aims to design and manufacture a prototype for low -cost smallscale essential oil distillation plant adaptable to the rural community. Considering the above characterization a low cost essential oil distillation plant was developed. The following are the main constraints used in the modelling of the distillation plant.

\section{Method of Essential Oil Production}

The quality of oil is a determinant factor for oil product to be competitive in the local or international market. Essential oils can be manufacture using different methods. Distillation (steam distillation, hydro- 
distillation, and water distillation), carbon dioxide extraction, cold pressing and solvent extraction are the methods used in the production of essential oils. These different methodologies have different impact on the quality of oil produced. The required technology sophistication is also dependent on the type of method used.

Taking a matrix of the above technology characterizations and experiences, steam distillation has been the best method for optimum conditions. Steam distillation has also it own ranges of technology sophistications. For our case where a group of farmers are going to own and operate the technology, the level of the sophistication has got limitation due to the low technical skills in the rural areas to operate the technology, the low investment required, and low infrastructure availability in the rural communities.

Steam distillation uses thermal energy in the extraction process and is a well-known technology method [De Silva,1998]. A steam produced in a satellite station (boiler) and fed to the still where the bio-material will be boiled to extract the oil inside and the required oil extract cooled in the condenser. Density difference method is used to separate the liquid mixture (water and oil) in the separator. Because of the satellite nature of the boiler, thermal degradation of oil is avoided which is common problem in other production methods. The thermal energy supply can be controlled according to the type of oil to be distilled. It is also the best way for energy efficiency which is one of the main costly inputs in the essential oil industry for mass production.

Though steam distillation requires high investment cost, it gives best oil quality compared to other distillation methods. The cost of investment and the quality have a direct connection to the quality of production and technology sophistication. Careful analysis is very important in reaching the optimum investment cost with keeping the other factors standard. One of the merits of the steam distillation is the opportunity in selecting the level technology, from the low to high technology depending on the investment required keeping the quality minimal change. A steam distillation system can be used for different type of aroma plants as the same time.
Technical Parameters in the Design of Steam Distillation System

In this project, experience in other developing countries is considered in selecting the optimum technology. The technology experience in Wondo Gent essential oil research center, South Ethiopia has also been a great input. Based on the cumulative economic and technical constraints, the model shown in figure 2 was designed. The plant has four main components, steam generator, still, condenser and separator. Each Component is discussed as below.

The steam generator of the plant is responsible for the production of the required amount of thermal energy in the form of steam to be fed to the still. Each part of the system is designed based on the availability of materials in local markets, energy resource, cost and local manufacturing capacity. The system can be operated with low technical skill level which can be attained in two-three day trainings. The boiler is a biomass-fired type to use the wood or any biomass resource available in the rural areas. The system is designed for maximum thermal efficiency. Thermal energy can be controlled using the readings on the pressure and temperature gages and manipulating the gate valve laying on tube line to the still.

The still is the most important part of the plant to keep the quality of oil produced. A still is where oil is displaced from the biomaterial placed inside by a steam coming from the steam generator. In the design of still, steam injection and distribution systems, insulation from the atmospheric condition plays important role in attaining the subjected quality and quantity of oil. Proper material handling system is also very important for easy operation and better efficiency. For this specific project, a universal still type for different type aroma plant is design based on local material and manufacturing capacity. The still is the expensive part of the plant. Stainless steel is used to avoid any contamination of oil as recommended by the literatures.

The condenser is responsible in the cooling of oil-water mixture to separate by density difference in the separator. The outlet temperature and the amount of the mixture steam coming from the still determine the size of the condenser and the cooling water required. The requirement of continuous cooling water in the condenser is sometimes a 
problem in rural communities. This problem can be solved using a height difference water tank and sighted close to a major water source like a perennial stream or river. The condenser is designed for optimum cooling water consumption, cost of materials and manufacturing, and its availability to the rural community.

Separator is the smallest but very important part of the system. The equipment is designed based on the immiscibility of oil and water so that oil can be separated by density difference. Most essential oils have density less than water. The separator is designed to keep the optimum separation process and the required volume for continuous operation.

\section{Manufacturing Aspects}

Manufacturing appears the most important part of any design. It is the stage when all the feasibility of any proposed design is tested and verified. The objective of the project is to manufacture a prototype and test. Low-cost manufacturing and participating small-scale manufacturing enterprises are the two main constraints used in the design for manufacturing processes of the project. It is known that small-scale-manufacturing enterprises have limited capacity and low technically skilled workers which limit the level of accuracy and size of the product. The advantage of agro-based small-scale manufacturing enterprises can be seen in two ways. The cost of manufacturing reduces in small-scale manufacturing enterprises as the same time it will help in the process of mitigating unemployment in urban areas. Large-scale manufacturing industries have a capacity of producing accurate products but expensive production.

The workshop of Mechanical Engineering Department has been used as host for manufacturing the prototype. Though enough machines are available, the workshop can be assumed as small-scale workshop due to the non-functionality of most machines available. Moreover, the technicians are not experienced in manufacturing such type of industrial plant. Assuming the workshop as small-scale workshop can help as to know which part can be manufactured in these workshops and which are not. Figure 3 shows the prototype manufactured in the departments workshop. The prototype is designed for 125 litres of still to hold an approximate of $50 \mathrm{~kg}$ of raw eucalyptus foliage and 80 litres of steam generator vessel for the required amount of steam production. Steam carrying component of the plant need precision manufacturing. High welding accuracy is required in the manufacturing of steam generator vessel and the still. Perfect tube fitting are required in the steam transportation. In order to manufacture these components, it requires skilled technician and capacity. The total plant components can be manufactured to the required level for both large and smallscale manufacturing industries.

Cost of manufacturing includes machine cost, labour cost and material cost. The above prototype is manufactured with a total cost 5012 Birr (\$505 USD) (birr is Ethiopian currency). Prototype manufacturing is always expensive compared with the mass production. Therefore the plant can be manufactured at less than 5000 birr while the imported plant with 33 litres still capacity (which is less than the designed capacity by a factor of 3.75) costs 22,000 Birr (\$2224 USD) excluding shipment cost (Woubneh, 2001). These values will even higher if it includes custom taxes and shipment costs.

\section{Conclusion}

Literatures and experiences showed that small scale industries are indispensable for the economic development of Ethiopia. Promotion and technology supports are crucial in the development of small-scale industries in the country. Technology development and adaptation should be based on the resource, socio-economic condition of the targeted entrepreneur and the end users of the product. For countries like Ethiopia where agrarian economy dominates and $85 \%$ the population live in rural, the development of agro-based small scale industries helps to bring a sustainable development in rural areas. Essential oil industry is one of the potential agro-processing industries not given adequate attention. Though Ethiopia favours the cultivation of high quality aroma plants for essential oil, the benefit of the sector in rural poverty alleviation is not evaluated by the policy.

Technological support is the very first agenda to be answered in the introduction of a new small-scale industry for an entrepreneur. Technological characterization is important to fix parameters in the design and development of a technology. The socio-economic condition of the targeted entrepreneur is the main 
constraint used in the characterization of the technology for small -scale industry.

One of the main objectives of developing low cost essential oil distillation plant was to design and develop a low cost distillation systems according to the characterization discussed. Getting the standard quality of oil to compete in the local and international market determines the accuracy of manufacturing essential oil distillation plant. The manufacturing process was supposed to involve small scale manufacturing industries for better contribution to job creation in urban areas. The

\section{Reference}

Coulter J. (1987) Market study for Frankincense and Myrrh from Somalia. Study undertaken for the European Association for Cooperation, Natural Resources Institute UK.

De Silva, T. (1998). Development Of Essential Oil Industries In Developing Countries, chemical Industries Branch Industrial Sectors And Environment Division, United Nations Industrial Development Organization

EI-Namki, M.S.S. (2003). Developing and promoting technology and technical skills in small scale rural manufacturing enterprises, FAO, United Nations.

Ho.S.P.S. (1980) Small Business and Industrialization in South Korea, Asian Pacific. Journal of Management, Vol.9 no.1 pp107-117 experience showed that it may not be possible to manufacture all the components of the plant in small-scale manufacturing industries for producing a standard oil quality. The integration of small and large-scale manufacturing industries can help in the manufacturing of a low cost distillation plant at affordable cost group of farmers. The problems seen in the design and manufacturing of first prototype, is an important input for the future works in introducing the small scale industry to the rural community.

Romijn H, (2001). Technology support for small scale industry in developing countries: A review of concepts and project practices, Oxford Development Studies, Vol. 29

Woubneh, T. (2001). Profile of the food processing industry in Ethiopia, united nations industrial development organization , Addis Ababa , Ethiopia

Worku, T. (2004). Ethiopia's Essentials?! Export potential of Ethiopian essential oils Ethiopian Promotion Department Large Essential Oil Steam Distillation Kits, 10 gallon/33 liter Bio-capacity, http://www.crucible.org/distillation.htm

Takeshi, Hayashi (1990). The Japanese experience in technology, from transfer to selfreliance, The United Nations University, 1990, Tokyo.

Ethiopia CSA (2002)- Central statistical Abstract, 2002, Addis Ababa, Ethiopia 


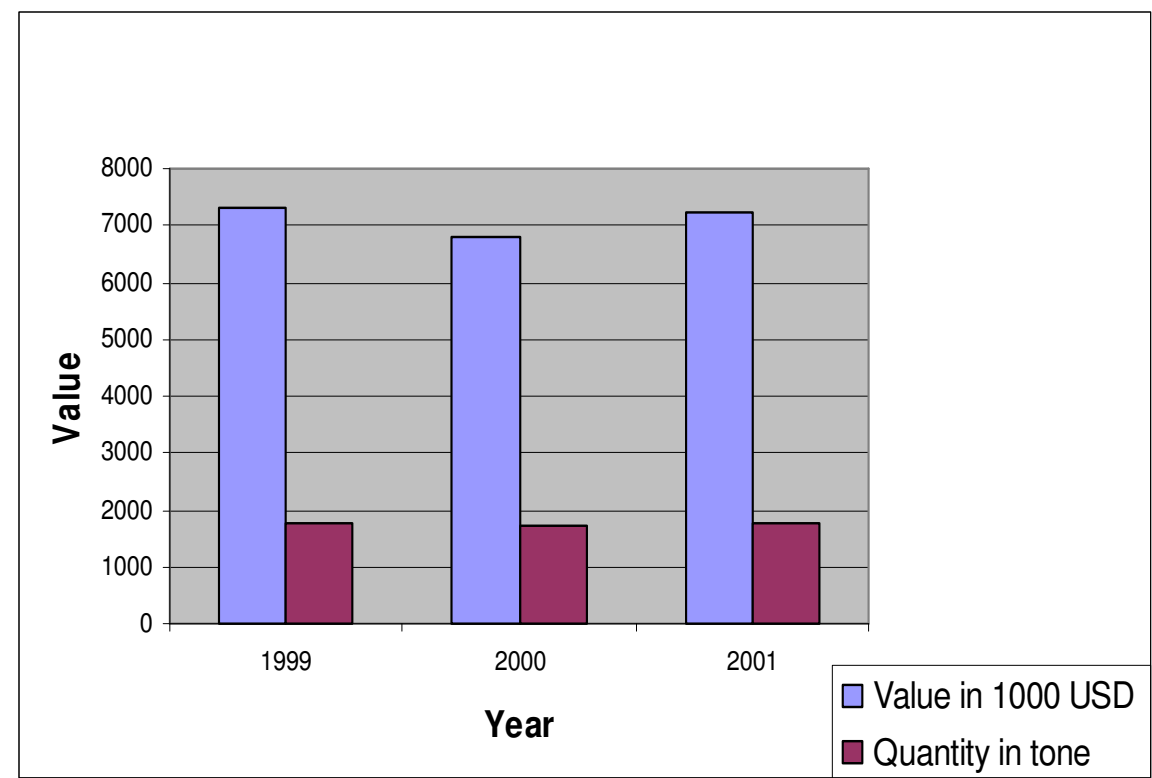

Fig 1. Ethiopian imports of Essential oils and allied products, 1999-2001. Source: Central statistical Abstract, 2002, Addis Ababa, Ethiopia

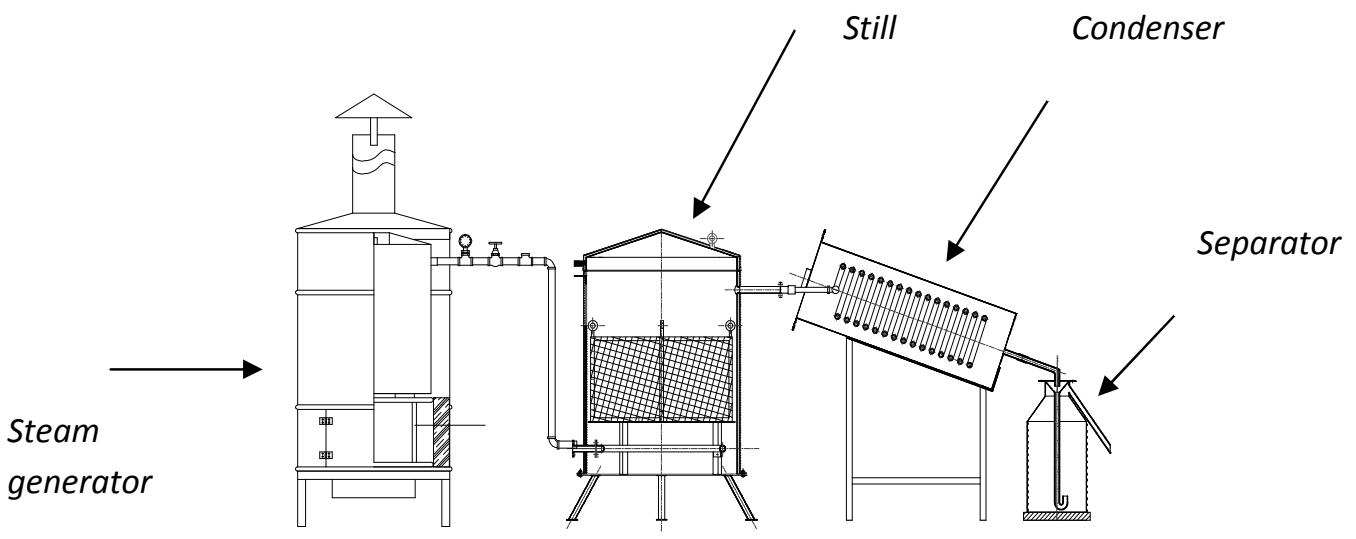

Fig.2 Modelled Steam distillation systems 


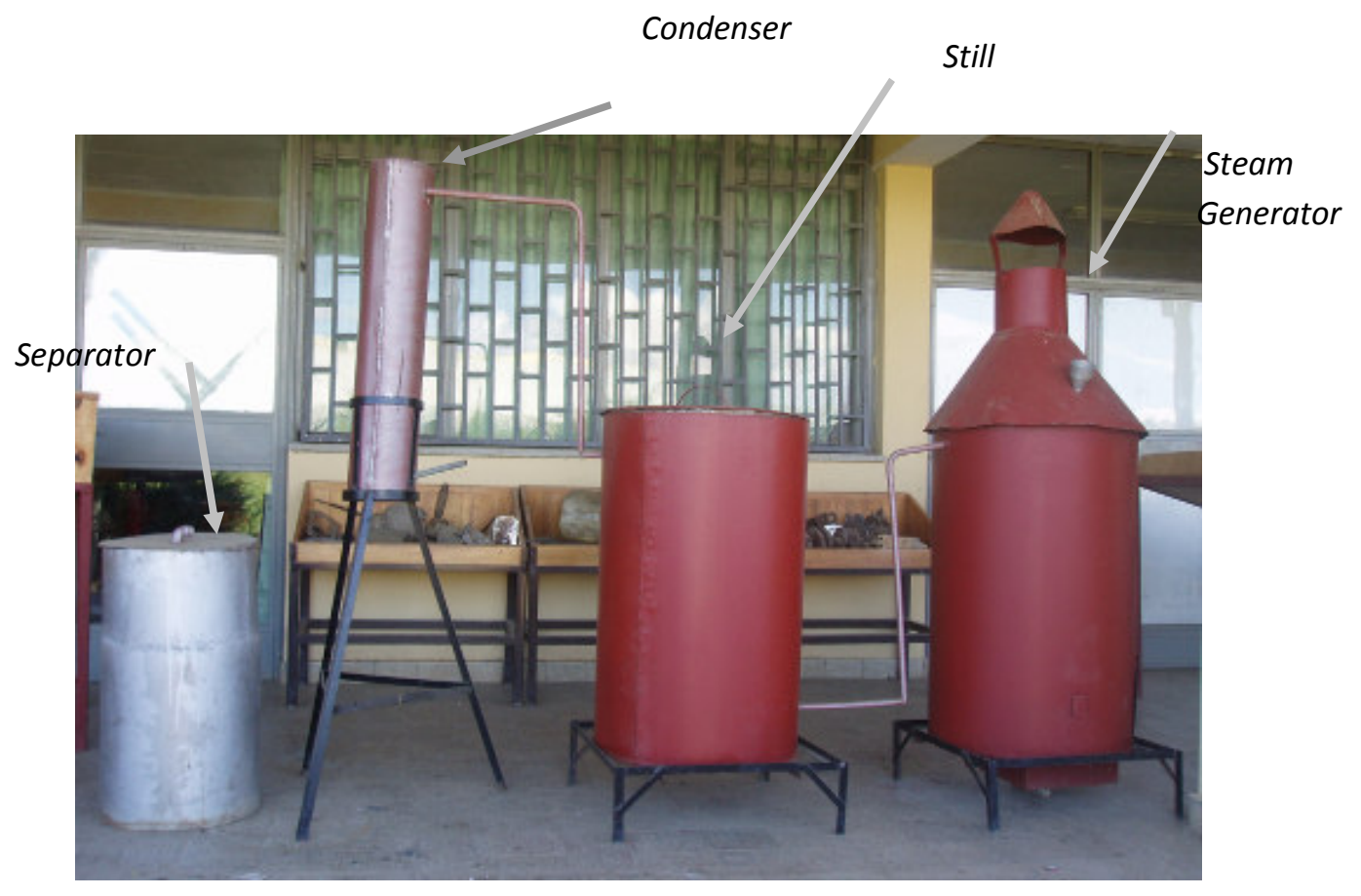

Fig. 3 First Prototype trial in the department of mechanical Engineering 